\title{
Effect of the Genotype and Growing Conditions on the Main Phenolic Compounds in Capsicum Peppers
}

\author{
Ana Maria RIBES-MOYA, Ana Maria ADALID-MARTíNEZ, Miguel Bracho GIL, Patricia ESTEVE-CIUDAD, \\ Pascual FERNÁNDEZ-DE-CÓRDOVA, María Dolores RAIGÓN, Adrián RODRIGUEZ-BURRUEZO* \\ Instituto de Conservación y Mejora de la Agrodiversidad Valenciana (COMAV), Universitat Politècnica \\ de València, Camino de Vera 14, 46022 Valencia, Spain \\ *corresponding author: adrodbur@doctor.upv.es
}

Bulletin UASVM Horticulture 75(1) / 2018

Print ISSN 1843-5262, Electronic ISSN 1843-536X

DOI:10.15835/buasvmcn-hort: 000817

\begin{abstract}
Capsicum peppers is one of the most important vegetables, with a well known nutritional properties, including phenolics. Breeding peppers adapted to organic agriculture and rich in bioactive compounds is of paramount importance for this sector since the demand of organic and healthy food is increasing in many countries. This is a preliminary study on the effect of genotype, growing conditions and their interaction on the main phenolics of peppers. Fruits from four Capsicum annuum (BGV-10582, Bierzo, Bola and Piquillo) and one C. chinense (ECU-994) accessions, were cultivated under organic and conventional practices and main phenolic compounds quercetin and luteolin were analysed by high performance liquid chromatography (HPLC). Differences were found among accessions for both compounds in the studied accessions, particularly ECU-994. Differences for each phenolic compound were also detected between growing systems. Moreover, considerable interaction between genotype and growing conditions was found, suggesting that there are ample opportunities for selecting peppers with high content in phenolics and specifically adapted to organic cultivation.
\end{abstract}

Keywords: organic agriculture, quercetin, luteolin

\section{Introduction}

Capsicum peppers is a vegetable of great economic importance in the world with a wide genetic diversity in Spain and their nutritional qualities are widely recognized, including high content in phenolics that are natural antioxidants (Belkhodja, 2017). In addition, the demand of organic and healthy food is increasing in many countries of EU (FAO, 2015), which offers a great opportunity to increase the acreage of this lowinput and sustainable agriculture and diversify the offer from growers since the most efficient use and exploitation of resources have become an essential requirement. Therefore, breeding peppers adapted to organic agriculture and rich in bioactive compounds is of paramount importance for the sector of vegetables in Spain, which is the country with the highest total organic area in the EU (Eurostat, 2015). The present work shows a preliminary study on the effect of genotype, growing conditions and their interaction on the levels of the main phenolic compounds in a selection of Capsicum peppers.

\section{Materials and methods}

The two main phenolic compounds quercetin and luteolin of four Capsicum annuum (BGV-10582, Bierzo, Bola and Piquillo) and one $C$. chinense (ECU-994) accessions, cultivated under organic and conventional growing practices in 2016 in Valencia (Spain) were studied. The fertilization for organic plot was based on organic sheep manure and pests were naturally controlled by predators. Conventional plot was fertilized with vegetable humus, mix of nitrogen, phosphorus and potassium, calcium nitrate and iron chelate. Plagues were controlled by chlorpyrifos, abamectin and copper oxychloride. Adventitious plants were controlled by manual clearing in both plots. Lyophilized pulp of mesocarp from fully ripe fruits was used, being 
Table 1. Average content of main phenolic compounds ( $\mathrm{mg} / \mathrm{kg}$ dry matter) estimated in fully ripe fruits of different pepper genotypes, evaluated under organic and conventional systems

\begin{tabular}{ccccccccc}
\hline \multirow{2}{*}{ Genotype } & \multicolumn{4}{c}{ QUERCETIN } & \multicolumn{5}{c}{ LUTEOLIN } \\
\cline { 2 - 11 } & \multicolumn{2}{c}{ Organic } & \multicolumn{2}{c}{ Conventional } & Organic & \multicolumn{2}{c}{ Conventional } \\
\hline BGV-10582 & 54.8 & $\mathrm{ab}^{1}$ & 67.3 & $\mathrm{ab}$ & 261.0 & $\mathrm{a}$ & 260.3 & $\mathrm{ab}$ \\
\hline Bierzo & 397.9 & $\mathrm{c}$ & 365.2 & $\mathrm{c}$ & 638.6 & $\mathrm{c}$ & 630.6 & $\mathrm{~d}$ \\
\hline Bola & 35.9 & $\mathrm{a}$ & 24.2 & $\mathrm{a}$ & 326.4 & $\mathrm{a}$ & 329.1 & $\mathrm{~b}$ \\
\hline ECU-994 & 78.8 & $\mathrm{~b}$ & 80.3 & $\mathrm{ab}$ & 211.9 & $\mathrm{a}$ & 208.4 & $\mathrm{a}$ \\
\hline Piquillo & 83.4 & $\mathrm{~b}$ & 132.7 & $\mathrm{~b}$ & 483.5 & $\mathrm{~b}$ & 482.5 & $\mathrm{c}$ \\
\hline Serrano & 23.1 & $\mathrm{a}$ & 18.4 & $\mathrm{a}$ & 267.0 & $\mathrm{a}$ & 242.4 & $\mathrm{ab}$ \\
\hline Total & $\mathbf{1 1 2 . 3}$ & $\mathbf{1 1 4 . 7}$ & $\mathbf{3 6 4 . 7}$ & $\mathbf{3 5 8 . 9}$
\end{tabular}

Note: ${ }^{1}$ Different letters show significant differences between mean values within each growing system (LSD test, $\mathrm{P}<0.05)$.

extracted by a modification of the Haejin Bae et al. (2012) method with a hydrochloric acid hydrolysis of flavonoid glycosides. Samples were analyzed by the HPLC method in a binary solvent system which consisted of $0.1 \%$ formic acid in water (A) and $0.1 \%$ formic acid in methanol (B), detection at 260 $\mathrm{nm}$ and Brisa $\mathrm{LC}^{2}-\mathrm{C}_{18}$ column $(3 \mu \mathrm{m}, 15 \times 0.46 \mathrm{~mm}$, Teknokroma, Barcelona, Spain).

\section{Results and discussion}

Genotype contributed considerably to the variation in phenolics, even higher than previously described by other authors (Bae, 2012; Materska, 2005). Thus quercetin levels were comprised between 23 and $398 \mathrm{mg} / \mathrm{kg}$ and between 18 and $365 \mathrm{mg} / \mathrm{kg}$ in organic and conventional growing systems respectively, while levels of luteolin ranged approximately between 200 and $630 \mathrm{mg} / \mathrm{kg}$ in both systems (Tab. 1). Bierzo was the accession with the highest values for both flavonoids ( $>350$ and $>600 \mathrm{mg} / \mathrm{kg}$ ) in both growing system, followed by Piquilllo. By contrast, Serrano and Bola showed the lowest values of quercetin, while the lowest luteolin levels were found in ECU994. Despite there were no differences on average between growing systems for both phenolics, differences for each phenolic compound were found in some cases (e.g. quercetin in Bierzo and Piquillo, luteolin in Serrano), suggesting the effect of genotype $x$ growing system interaction. Such interaction between genotype and growing conditions was found, suggesting that accessions with high phenolic content levels under organic cultivation can be selected.

\section{Conclusion}

Our results suggest that there are ample opportunities for selecting pepper varieties like Bierzo and Piquillo with a rich phenolic compounds profile and adapted to organic cultivation.

Acknowledgements. This work was partly financed by project RTA2014-00041-C02-02, funded by the Inst. Nacional Investigaciones Agrarias (Spain), FEDER funds.

\section{References}

1. Belkhodja H, Belmimoun A, Meddah B (2017) Chemical characterization of polyphenols extracted from different honeys, Banats journal of biotechnology, 8(15): 78-82, DOI: 10.7904/2068-4738-VIII(15)-78

2. Eurostat (2016). Consultation statistics. http://ec.europa. eu/eurostat/statistics-explained/ index.php/Organic_ farming_statistics\#Total_organic_area

3. FAO (2015). Consultation statistics. http://www.fao. org/economic/ess/ess-publications/ essyearbook/faostatistical-yearbook-2011/es/y http://faostat3.fao.org/

4. Bae H, Jayaprakasha GK, Jifon J, Patil BS (2012). Extraction efficiency and validation of an HPLC method for flavonoid analysis in peppers. Food Chemistry, 130: 751-758.

5. Bae H, Jayaprakasha GK, Jifon J, Patil BS (2012). Variation of antioxidant activity and the levels of bioactive compounds in lipophilic and hydrophilic extracts from hot pepper (Capsicum spp.) cultivars. Food Chemistry, 134(4): 19121918.

6. Materska M, Perucka I (2005). Antioxidant activity of the main phenolic compounds isolated from hot pepper fruit (Capsicum annuum L.). Journal of Agricultural and Food Chemistry, 53(5): 1750-1756. 


\title{
Contributions Regarding the Creation of the Digital Map of the Public Transport in the Metropolitan Area of Cluj
}

\author{
Voichiţa ROIB*, Ilinca ROIB \\ Faculty of Civil Engineering, Technical University of Cluj-Napoca, 15 C-tin Daicoviciu, 400020 Cluj- \\ Napoca, Romania \\ *corresponding author: Voichita.Roib@mtc.utcluj.ro
}

Bulletin UASVM Horticulture 75(1) / 2018

Print ISSN 1843-5262, Electronic ISSN 1843-536X

DOI:10.15835/buasvmcn-hort: 002317

\begin{abstract}
A special importance in the stimulation of the public transport use, is the increase of the informing degree of travellers with regards to the transport networks. The paper presents technical data regarding the making of the digital map of the public transport in the metropolitan area of Cluj. The digital map was created by the authors, using data from Open Street Map site and data collected with the help of GPS, made available by Public Transport Company Cluj-Napoca S.A. The digital map created for public transport in the Municipality of Cluj-Napoca and Metropolitan Area of Cluj, with detailed maps routes, offers to users, information on public transport which leads to the efficiency of services and passengers' safety, increasing mobility and sustainability of Cluj-Napoca city.
\end{abstract}

Keywords: digital map, public transport, travellers' informing

\section{Introduction}

In order to satisfy the requirements of a safe, quick and comfortable travel of population it is necessary to inform the travellers about the public transport network by the use of a map containing the public transport routes, (Banciu et al., 2003). The urban public transport represents a public service made available for the population of the city, generating certain advantages such as: decrease of toxic pollution, urban space occupation, efficacy of the transportation. The main characteristic of the urban public transport consists in the necessity of executing an optimal offer when the need appears. In order to stimulate the use of public transport, it is necessary to organise it so as to ensure the development of travel with an adequate degree of safety and comfort. An important role in this regard is the increase of the travellers' information degree, with regards to the transport network, circulation schedules of the lines or the possibility to choose the optimal travelling route.
Aims and objectives. One of the priorities of Public Transport Company Cluj-Napoca S.A (CTP-Cluj-Napoca) regarding the improvement of the local public transport services, is to offer to travellers useful information with regards to the public transport. The paper presents technical data regarding the making of the digital map of the public transport in the metropolitan area of Cluj.

\section{Materials and methods}

The map of the public transport in the Metropolitan Area of Cluj was created so as to offer the possibility of being visualised by accessing the CTP Cluj-Napoca website, using the internet connection from PC, smartphone or tablet. Also, the map may be listed and posted and can be found on travel tickets selling machines, located in certain public transport stations in the municipality.

The digital map was created by the authors, using data from Open Street Map site, these being 


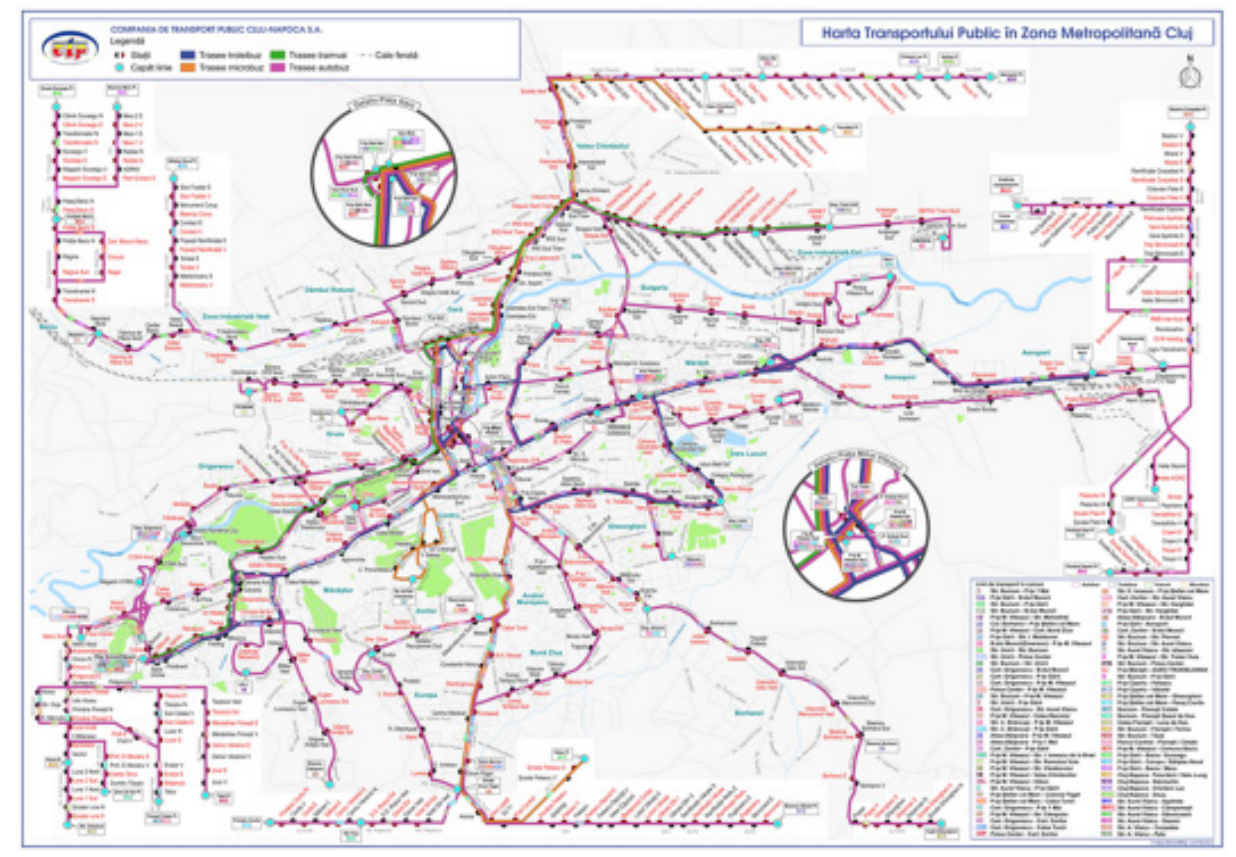

Figure 1. Public transport map in the metropolitan area of Cluj (CTP Cluj-Napoca)

„open source" data. In order to download them, the Open Street Map plugin was installed in QGIS (Open Source Geographic Information System), (QGIS). The downloaded data were gross data, of which only the data necessary to the execution of the public transport network map has been selected (for instance: street, water cruse, vegetation, railways).

For the creation of maps, CTP-Cluj-Napoca made available to the author, data collected with the help of GPS (Global Positioning System) for the routes, localisation of stations, travel tickets selling machines and ticketing system selling centres, in order to be used in the execution of the digital maps. For the finalisation of the maps, the necessary visual elements have been added, by using Inkscape, a vector graphic editing application.

\section{Results and discussion}

Starting on July 2015, CTP Cluj-Napoca launched a new website on internet, offering detailed information regarding the transport lines, timetables, fees and associated maps. On the company's site, www.ctpcj.ro, the current public transport maps in jpg. and pdf. format can be found (Fig. 1), including details related to the entire transport network and offering information to travellers, meant to increase the quality of the transport services and to promote the use of the public transport.

On the public transport map, planimetry elements can be found, such as physical and geographical elements (water courses, lakes in the municipality, green areas) administrative details (neighbourhoods of the municipality), street network. On the detailed map of the transport lines, the main touristic and cultural objectives, objectives of public interest, hospitals, churches and education units near routes have been marked. Also, the map contains other elements, such as: title, legend, North arrow, labels and explanations.

In order to identify the different transport lines forming the urban public transport network, the stations, the lines end points or travel tickets selling machines, a symbolic language was used, explained in the legend. In order to differentiate the means of transport or the stations located in different directions, different colours have been used, for a better recognition. The routes in the metropolitan area have been represented on the public transport map as a scheme, detailed maps being assigned to each metropolitan transport line.

\section{Conclusion}

The map created, together with the detailed maps of the transport lines, has a simple and user- 
friendly design, offers to users information related to the public transport lines and routes, location of stations, lines end points, travel tickets selling machines, all these leading to a better organisation of the travels, to the choice of the optimal travelling route and to the increase of the attractiveness of public transport services.

Acknowledgements. We are thankful to Public Transport Company Cluj-Napoca S.A, for the data made available through the collaboration Protocol, through which made it possible to create the public transport maps in the Municipality of Cluj-Napoca and Metropolitan Area of Cluj.

\section{References}

1. Banciu D, Hrin R, Mihai G, Eşanu A, Alexandrescu M, Anghel L (2003). Sisteme Inteligente de Transport - ghid pentru utilizatori şi dezvoltatori, Editura Tehnică București.

2. CTP Cluj-Napoca. http://ctpcj.ro/index.php/ro/. Accessed 15.06.17

3. QGIS Documentation. http://www.qgis.org/ro/site/. Accessed 15.06.17 